\title{
Letters
}

Website: bmj.com

\section{Length of consultations}

\section{Contract needs to enable doctors to offer} first class care

EDITOR-Jenkins et al found that patients vary both in what they want from a consultation with their general practitioner and in what they get. ${ }^{1}$ They found a poor correlation between these and the length of the consultation. The catchy front cover headline "Consultations don't have to be longer to be better" seriously overgeneralises these results. Some short consultations may be highly effective, but a systematic review earlier this year summarised a range of patient outcomes that are improved when doctors have more time. ${ }^{2}$

In one large English survey 12\% of patients complained about having insufficient time with their general practitioner, but this figure rose to $30 \%$ when patients were seen for five minutes or less. ${ }^{3}$ It may be that the doctors need additional time in consultations-perhaps more than their patients. Medical practice has become more complex, and more needs to be done during the course of consultations. This may explain why clinical care is inferior in practices with short consultations. ${ }^{4}$ Patients may sometimes get what they want in short consultations-but they may not always realise that it isn't good medical care.

It is 16 years since David Morrell and I and colleagues published the first experimental study showing the limitations of short consultations. ${ }^{5}$ It is well past time to consign surgeries booked at intervals as short as five minutes to history. The current payment system for general practitioners encourages a "pack 'em in and sell 'em cheap" approach to general practice. This needs to be addressed in the contract currently being negotiated so that all

\section{Advice to authors \\ We would like to receive all responses electronically at our website. Please send your letter directly to bmj.com as a rapid response to a published article. \\ All rapid responses will be considered for publication in the paper journal; authors will be notified by email if their rapid response has been accepted, but not otherwise. \\ For more detailed advice please see bmj.com/advice/sections.shtm\#letters \\ bmj.com}

general practitioners have time to offer their patients first class care.

Martin Roland director

National Primary Care Research and Development Centre, University of Manchester, Manchester M13 9PI

m.roland@man.ac.uk

1 Jenkins L, Britten N, Barber N, Bradley C, Stevenson F. Consultations do not have to be longer. $B M J$ Consultations do not

2 Freeman GK, Horder J, Howie JGR, Hungin P, Hill AP, Shah NC, et al. Evolving general practice consultation in Britain: issues of length and context. BMJ 2002;324:880-2 3 Department of Health. The national survey of NHS patients: general practice: 1998. www.doh.gov.uk/public/ nhssurvey.htm (accessed 1 Nov 2002).

4 Campbell SM, Hann M, Hacker J, Burns C, Oliver D, Thapar A, et al. Identifying predictors of high quality care in English general practice: observational study. $B M$ 2001;323:784-7.

5 Roland MO, Bartholomew J, Courtenay MJF, Morris RW, Morrell DC. The five minute consultation: effect of time constraint on verbal communication in the consultation. BMJ 1986;292:874-6.

\section{Consultations should be longer}

EDITOR-Consultations are infinitely variable and difficult to research quantitatively. After the better part of 20 years attempting to do this, we think the following conclusions can be safely drawn. In longer consultations, long term comorbidity and psychosocial problems as well as the presenting complaint are more likely to be recognised, and, having been recognised, they will be addressed. More health education is also likely to be offered. Patients and doctors are more likely to be satisfied.

We have identified a subset of satisfaction-like questions (which include important outcomes such as patients understanding their problems better and feeling more able to cope) as enablement. We have consistently found that doctors who enable more people, and who enable people more, are those whose average consultation time is longer. Their patients also know them better (a proxy for continuity). An association therefore exists between longer consultations and better processes and outcomes; we cannot say to what extent the relation is causal, although it is reasonable to say that it will be at least in part. Almost certainly, further important variables-for example, empathy-are also important correlates, but these too are difficult to research. ${ }^{2}$

No one has ever suggested that all long consultations are good ones, or that short ones cannot be effective, and Jenkins et al did not imply that. ${ }^{3}$ We argue that, although an individual consultation does not have to be long, doctors who on the whole provide shorter consultations are likely to be providing less good care. Similarly, patients who have never had the opportunity for longer consultations are unlikely to have their wants met.

At a time when sensitive negotiations on the contract for general practitioners are in progress, scientifically simplistic headlines such as those the $B M J$ has used serve neither doctors nor patients well. The message should be that consultations do have to be longer. We still believe that there should also be a contractual reward or incentive for providing such a service. ${ }^{2}$

David J Heaney research fellow david.heaney@ed.ac.uk

Margaret Maxwell senior research fellow John Howie retired professor of general practice Department of Community Health Sciences-General Practice, University of Edinburgh, Edinburgh EH8 9DX

1 Howie JGR, Porter AMD, Heaney DJ, Hopton JL. Long to short consultation ratio: a proxy measure of quality of care for general practice. BrJ Gen Pract 1991;41:48-54.

2 Howie JGR, Heaney DJ, Maxwell M, Walker JJ, Freeman GK. Developing a 'consultation quality index' (CQI) for use in general practice. Fam Pract 2000;17:455-61.

3 Jenkins L, Britten N, Barber N, Bradley C, Stevenson F. Consultations do not have to be longer. BMJ 2002;325: 388. (17 August.)

\section{Longer consultations can improve patient} satisfaction

EDITOR-Jenkins et al indicate from a general practice perspective that consultations do not have to be longer to achieve benefit. ${ }^{1}$ What they do not address is the nature of the consultation. Clearly, if it is about a wart, an attack of acute bronchitis or urinary tract infection, a rash, or whether to smoke, the consultation can be succinct and short. But what about when a patient comes with a problem that has been beset with publicity arising from politicians and sensational and one sided media coverage? In such circumstances, when the problem is multifactorial, time is of the essence.

In this department we see patients referred both by military and civilian doctors. The common complaint has always been that there has never been enough time to talk about the issues involved. Here, because we need the time, and indeed have the time, average consultations are one and a half hours per patient. As a result of this approach, we have a $95 \%$ patient satisfaction rate in questionnaires completed by patients when they leave. Such data have been collected on an anonymised, aggregated basis. 
We do not believe that generalisations can be made. Our experience has been that longer consultations have resulted in higher patient satisfaction rates. Our perspective is that patients would agree that longer consultations result in more satisfactory outcomes.

Harry A Lee professor and head of Gulf veterans' medical assessment programme

Baird Health Centre, St Thomas's Hospital,

London SE1 7EH

brenda.hazelwood@gstt.sthames.nhs.uk

1 Jenkins L, Britten N, Barber N, Bradley C, Stevenson F. do be longer. BMJ 2002, 325:388. (17 August.)

\section{Time and stress are limiting holistic care in Scotland}

EDITOR-Freeman et al, in their paper on consultation length in relation to quality of care in general practice in the United Kingdom, have provoked responses that highlight the complexity and question the benefit of providing longer consultations..$^{1-3}$ The need for a shift in focus to the content of the consultation, rather than time itself, has also been raised. ${ }^{4}$ We report the findings of a national survey of the views of Scotland's general practitioners on holism in primary care.

We sent a postal survey to all 3713 principals in general practice in Scotland in February 2001. The overall response rate was $62.2 \%$ (2311) after two postal reminders. Respondents were similar to the total workforce of principals in general practice in terms of age and sex, although more part time general practitioners were represented in the sample compared with the total workforce (part time 552; 23.9\% sample $v 620$; $16.7 \%$ total general practitioners' workforce). Locality of practice was recorded as urban $(1076,46.6 \%)$, rural $(749,19.9 \%)$, or mixed $(461,32.4 \%)$ and socioeconomic area of the practice as high deprivation (380, $16.4 \%)$, medium/mixed (1015, 43.9\%), marginal deprivation $(537,23.2 \%)$, or no deprivation (339, 14.7\%).

Nearly nine out of 10 general practitioners $(1925 / 2205,87.3 \%)$ believed that a holistic approach was essential to providing good health care, but only one in 15 $(158 / 2311,6.8 \%)$ thought the current organisation of primary care services made it possible. The main constraint on holism in the consultation was seen as the time available, followed by the general practitioner's own stress level. Mean values $(95 \%$ confidence intervals) for constraints, rated on a scale of 0 (not limiting) to 10 (extremely limiting), were: time 7.6 (7.49 to 7.67 ), stress 4.9 (4.84 to 5.04), training 4.7 (4.66 to 4.84 ), skills 4.2 (4.13 to 4.30), motivation 3.4 (3.33 to 3.50 ), attitudes of partners 2.9 (2.82 to 3.02 ), and own personality 2.6 (2.51 to 2.66 ). General practitioners working in urban, high deprivation areas felt more constrained by time and stress than general practitioners in the other areas (Kruskal-Wallis $\mathrm{H}$ test, $\mathrm{P}<0.005$, results not shown). Additionally, general practitioners working in full time employment reported higher levels of stress than those working part time $(\mathrm{P}<0.005$, results not shown).

Scotland's general practitioners believe that holistic care is being critically constrained by organisational factors. Time and stress are the top two issues in the consultation. These results give voice to deep concerns among a nation's general practitioners who remain committed to a holism they are struggling to deliver.

Stewart W Mercer general practitioner

Department of General Practice, University of Glasgow, Glasgow G12 ORR

stewmercer@blueyonder.co.uk

Harutomo Hasegawa medical student University of Glasgow

David Reilly consultant physician

Department of Medicine, University of Glasgow

Annemieke P Bikker research fellow

ADHOM Academic Departments, Glasgow

G12 0NR

ADHOM is the identifying logo of the Academic Departments, a substructure of the AdHominem charity.

1 Freeman GK, Horder JP, Howie JGR, Pali Hungin A, Hill AP, Shah NC, et al. Evolving general practice consultation in Britain: issues of length and context BMJ 2002; 324:880-2. (13 April.)

Wilson P, McConnachie A, Stirling M. Increasing consulta

J

Cons britten N, Barber N, Bradley C, Stevenson F. Consultations do not have to be longer. BMJ 2002;

4 Sturmberg JP. The third consultation dimension-focusin on content [electronic response to Freeman GK, et a Evolving general practice consultation in Britain: issues of length and context]. bmj.com 2002. bmj.com/cgi/eletters $324 / 7342 / 880 \# 22226$

\section{Telephone consultations may not save time}

EDITOR-Oldham describes how telephone consultation has apparently reduced the need for face to face consultations for patients requesting same day appointments in general practice. ${ }^{1}$ But on the basis of his own figures (if as I assume all such requests were triaged), almost half of those spoken to on the telephone went on to be seen by a doctor anyway. Depending on how long the telephone contact took, added to the follow up appointment, savings in time on those managed by phone alone would have been minimal.

My colleagues and I performed a small randomised control trial of telephone versus face to face consultation for requests for same day appointments. ${ }^{2}$ We found, as did Oldham, that around half could be managed by telephone alone. We timed all contacts and found that the average time spent phoning and in discussion with patients was 5.2 minutes, the average face to face appointment was 8.2 minutes, and the average time taken for combined telephone triage followed by face to face was $10.9 \mathrm{~min}$ utes. In addition, and more worryingly, patients dealt with by telephone alone reconsulted 1.5 times more than those dealt with face to face $(\mathrm{P}=0.01)$, probably wiping out any small gains made.

We also found that the process of telephone consulting led to a notable reduction in opportunistic health promotion (using blood pressure measurement as a marker).

While the idea of using telephone triage for same day appointments is seductive and superficially seems to be cost effective, further research is required before its widespread adoption.

Brian H McKinstry senior researcher

Department of Community Health Sciences, University of Edinburgh, Edinburgh EH8 9ER brian.mckinstry@ed.ac.uk

1 Oldham J. Telephone use in primary care. BMJ 2002;325:547. (7 September)

2 McKinstry B, Walker J, Campbell C, Heaney D, Wyke S. Telephone consultations to manage requests for same day appointments: a randomised controlled trial in two practices. Br J Gen Pract 2002;52:306-10.

\section{Value of knee imaging by GPs requires rigorous assessment}

EDITOR-In his editorial McNally reports that magnetic resonance imaging has had a great effect on the management of internal derangement of the knee and is increasingly available to hospital specialists and general practitioners. ${ }^{1}$ Whether general practitioners' access to imaging has as great an effect as use by a knee specialist, however, is not known. ${ }^{2}$ This question is crucial to patient management and outcome, and thus to cost effectiveness.

Access to magnetic resonance imaging by general practitioners for patients with knee problems could result in early diagnosis. Negative results could allow general practitioners to reassure patients, treat them conservatively, and avoid unnecessary hospital referrals, surgery, and associated costs. Positive results could confirm general practitioners' clinical diagnoses and ensure that urgent cases are seen more quickly by hospital specialists. ${ }^{3}$ This would ensure that surgeons were more likely to see patients who would benefit from a consultation, with the potential to reduce average waiting times, increase efficiency, and even improve patient prognosis and quality of life.

Although magnetic resonance imaging allows accurate assessment of meniscal and ligamentous injuries and avoids expensive invasive arthroscopy, ${ }^{2}$ no rigorous evidence shows whether it improves patient quality of life and reduces costs. The variation in general practitioners' access to, and use of, such imaging is also wide. ${ }^{5}$ This variation has been politically driven rather than evidence based, as the distribution of scanners reflects the past demands of fundholding general practitioners. So it is timely to ask whether access to this reliable diagnostic tool in primary care can achieve its potential.

The Medical Research Council has recently funded a multicentre randomised trial to help resolve the uncertainty about whether general practitioners should refer patients with internal derangement of the knee for magnetic resonance imaging or directly to an orthopaedic surgeon. We shall recruit 500 patients from over 250 general practices in north Yorkshire, north Wales, 
and north east Scotland and follow them up over 24 months. The trial will inform policy on whether to increase open access for general practitioners or to restrict magnetic resonance imaging to secondary care at the request of orthopaedic surgeons.

As McNally describes, magnetic resonance imaging of the knee is accurate and can help inform therapeutic decisions. But its use is already consuming substantial NHS resources without evidence of whether it improves patient outcome. Access to magnetic resonance imaging by general practitioners is at risk of becoming standard policy without rigorous evaluation.

Stephen Brealey research fellow

Ian Russell professor in health sciences

Department of Health Sciences, University of York, York YO10 5DD

Fiona Gilbert professor in radiology

Department of Radiology, Aberdeen AB25 2ZD

1 McNally EG. Magnetic resonance imaging of the knee BMJ 2002;325:115-6. (20 July.)

2 Correspondence Direct access magnetic resonance imaging of the knee for GPs. BMJ 1996;312:849-50.

3 A Apthorp LA, Daly CA, Morrison ID, Field S. Direct acces to MRI for general practitioner 4 Mackenzie R, Palmer CR, Lomas DJ, Dixon AK. Magnetic resonance imaging of the knee: diagnostic performance studies. Clin Radiol 1996:51:251-7.

Robling M, Kinnersley P, Houston H, Hourihan M, Cohen D, Hale J. Exploration of GPs' use of MRI: a critical incident study. Fam Pract 1998;15:236-43.

\section{Hormone replacement therapy}

\section{Logically, long term hormone replacement therapy cannot be recommended}

EDITOR-Stevenson and Whitehead are unable or unwilling to draw the logical conclusion from the women's health initiative study. ${ }^{2}$ Long term hormone replacement therapy cannot be recommended as the risks associated with it are more than the benefits.

The editorial shows the difficulty we have in telling women the truth. Hormone replacement has been recommended to women more on promises and is based on very poor evidence of benefits. Even the recommendation for prevention of fracture is based on weak evidence. ${ }^{3}$ Stevenson and Whitehead urge the use of nonmedroxyprogesterone based preparations and lower doses of equine oestrogen on a theoretical basis. I hope that general practitioners won't get into the farce of changing treatment on the basis of this advice and giving the patients the impression that they know what they are doing.

The authors point out that the oestrogen alone arm of the study is still continuing. This does not mean that oestrogen on its own is safe. A recent meta-analysis of observational data adjusted for baseline variables published after the editorial is consistent with the randomised trial data that the hormone replacement does not prevent cardiovascular events. ${ }^{4}$

Most commentators have concentrated on the risks highlighted in the women's health initiative study as small. What is not highlighted is that the benefits (decrease in colon cancer and fracture risks) are even smaller than the risks. Although the risks to an individual are small, the potential harm is great for the population of women taking hormone replacement, and on this basis alone it should not be recommended. The results are even more significant when one considers that $46 \%$ of the women receiving active treatment discontinued taking it and the results are analysed on an intention to treat basis. Over 5.2 years one in 100 women had adverse events.

Kishore Shetty general practitioner

Pallion Health Centre, Sunderland SR4 7XF kishoreshetty@hotmail.com therapy. BMJ 2002:325:113-4. (20 July.) tors. Risks and benefits of estrogen plus progestin in healthy postmenopausal women. JAMA $2002 \cdot 288 \cdot 321-39$. Lancet 2002:359:26.
Lest of postmenopausal osteoporosis.

Humphrey LL, Chan BKS, Sox HC. Postmenopausal hormone replacement therapy and the primary prevention

\section{Public health concern is serious}

EDITOR-In contrast to Stevenson and Whitehead we think that the women's health initiative trial's results on oestrogen plus progestogen treatment in postmenopausa women are of great concern because of their potential public health implications. ${ }^{12}$ The authors emphasise that their results on end points probably underestimate the true impact because they analysed the data according to intention to treat. Thus they conclude that eight additional cases of invasive breast cancer would arise per 10000 women treated per year.

This, however, can be applied only to a population of women who-similar to women included in the women's health of oestrogen-progestogen combination drugs. We recently conducted a representative telephone survey on women aged 40-69 in the north German city of Bremen and found a much longer lifetime intake in a considerable proportion of Bremen city residents, ranging from 3.4 years in 40-44 year old women to 11.1 years in $65-69$ year old women.

As Fletcher and Colditz said in commenting on the women's health initiative trial's principal results paper, the detrimental results probably can also be applied to oestrogen-progestogen combination drugs with different formulations. ${ }^{3}$ To appraise the public health impact it would be helpful to have a figure on risk increase per year of use. Fortunately the original paper provided data (in table 4) to derive such an indicator. Using meta-analysis methods we calculated Mantel-Haenszel relative risks, confidence
1 Stevenson JC, Whitehead MI. Hormone replacement

2 Writing group for the Women's Health Initiative investigahelm PD. Treatment of postmenopausal 288.521-3 . initiative trial-receive only about five years

intervals, and variances for years $1-5$ of the study as well as the summary relative risk increase per year of use.

The table shows that the MantelHaenszel estimates of relative risks were nearly identical with those presented in table 4 of the original paper. The calculated risk increase per year of $10.4 \%$ is consistent with annual increases observed in recent large epidemiological studies of $7 \%$ and $8 \%{ }^{4}$

For the public perception of the results of the women's health initiative trial, it is more graphic to point out that an average women aged 65-69 will more than double her risk of breast cancer risk with more than 11 years of oestrogen-progestogen hormone therapy.

Eberhard Greiser director greiser@bips.uni-bremen.de

Claudia Steding postgraduate student of epidemiology and public health

Klaus Giersiepen professor, Bremen State Cancer Registry

Katrin Janhsen clinical pharmacist, Division of Social Medicine and Pharmacoepidemiology

Bremen Institute for Prevention Research and

Social Medicine, Centre for Public Health,

University of Bremen, Linzer Strasse 8-10, D-28359

Bremen, Germany

1 Stevenson JC, Whitehead MI. Hormone replacement therapy. BMJ 2002:325:113-4. (20 Julv.)

2 Writing Group for the Women's Health Initiative Investigators. Risks and benefits of estrogen plus progestin investigators. Risks and benefits of estrogen plus progestin in healthy postmenopausal women. Principal results from the Women's Health In

in Fletcher SW, Colditz GW. Failure of estrogen plus proges
tin therapy for prevention. JAMA 2002;288:365-368.

tin therapy for prevention. JAMA 2002;288:365-368. HO, Persson I. Breast cancer risk following long-term oes$\mathrm{HO}$, Persson I. Breast cancer risk following long-term oes-
trogen and oestrogen-progestin replacement therapy. Int J Cancer 1999;81:339-44.

5 Schairer C, Lubin J, Troisi R, Sturgeon S, Brinton L, Hoover R. Menopausal estrogen and estrogen-progestin replacement therapy and breast cancer risk. JAMA 2000;283:485-91

* See also the published letter by J Michael Dixon (2 November, p 1036), which unfortunately became uncoupled from this clusterSharon Davies, letters editor.

\section{Authors' reply on reducing adolescent unintended pregnancy}

EDITOR-Noar points out that control participants in most studies in our systematic review received conventional sex education. ${ }^{12}$ Therefore, the appropriate conclusion is that more intensive, theory based programmes do not improve outcomes beyond what is achieved by conventional programmes. We agree, and we said so in our paper.

Noar challenges us to provide an explanation for why some programmes are effective and others are not. This question assumes that some programmes are effec-

Relative risk for invasive breast cancer by year of treatment with oestrogen plus progestogen in the women's health initiative trial (table 4), ${ }^{2}$ calculated by using Mantel-Haenszel estimates for relative risks and $95 \%$ confidence intervals

\begin{tabular}{ccccccc} 
& Year 1 & Year 2 & Year 3 & Year 4 & Year 5 & \% risk increase/year \\
\hline RR $(95 \% \mathrm{Cl})$ & 0.62 & 0.83 & 1.16 & 1.74 & 2.65 & 10.4 \\
& $(0.32$ to 1.20$)$ & $(0.5$ to 1.37$)$ & $(0.66$ to 2.06$)$ & $(0.97$ to 3.12$)$ & $(1.21$ to 5.84$)$ & (1.2 to 20.4)
\end{tabular}


tive. We see little evidence to substantiate this view. As we pointed out in a previous review, apparent effectiveness has been related to study design. ${ }^{3}$ Observational studies show effects, randomised trials do not. We interpret these results as suggesting that bias, rather than true intervention effects, explains the apparent treatment impact reported in the observational studies. Before we can explain why some interventions are effective, we need solid evidence of effectiveness. Such evidence remains unavailable.

Currently, most schoolchildren in the United Kingdom, United States, and Canada receive some form of sex education. And yet, rates of adolescent pregnancy in these countries remain alarmingly high (rates ranging from 43 to 93 pregnancies per 1000 young women aged 15 to 19 years). Clearly, neither conventional programmes nor those evaluated in the studies included in our review are having their intended effect.

Effective interventions are likely to emerge only with a deeper understanding of the problems. Such understanding may arise from research that examines the social determinants of unintended pregnancy among young people, the characteristics of countries with low pregnancy rates in young people, the characteristics of effective programmes to prevent other high risk behaviours in young people, and suggestions from young people. Clearly, effective prevention of adolescent pregnancy remains a research frontier.

Alba DiCenso professor, school of nursing Gordon Guyatt professor, department of clinical epidemiology and biostatistics

McMaster University, 1200 Main Street West,

Hamilton, ON, Canada L8N 3Z5

dicensoa@mcmaster.ca

1 Noar S, Spencer N. Reducing unintended pregnancy among adolescents. BMJ 2002;325:777-8. (5 October.)

2 DiCenso A, Guyatt G, Willan A, Griffith L. Interventions to reduce unintended pregnancies among adolescents: reduce unintended pregnancies among adolescents:
systematic review of randomised controlled trials. BMJ 2002;324:1426-34. (15 June.)

3 Guyatt GH, DiCenso A, Farewell V, Willan A, Griffith L Randomized trials versus observational studies in adolesRandomized trials versus observational studies in adoles-
cent pregnancy prevention. J Clin Epidemiol 2000;53:167-74.

\section{Currency conversion is not only issue in effectiveness studies}

EdITOR-Gosden and Torgerson mention that currency conversions make the use of foreign pharmacoeconomic analyses of questionable value. ${ }^{1}$ I agree that currency conversion is a difficult task, particularly when the euro to dollar exchange rate has gone from 1:0.80 to 1:1.08 in less than two years. But the problem of external validity or usefulness in other settings goes far beyond currency conversion issues.

Even in the same country, published analyses tend to be of little value because the underlying prices or costs of the drug treatments and other resources tend to vary dramatically between institutions. Drugs that were prohibitively expensive in one analysis can be most dominant (both more effective and less expensive) from another institution's perspective.

In the United States some authors try to get around this problem by using published average wholesale prices supplied by the manufacturer. These are, however, usually a dramatic overstatement of the amounts paid by any real purchaser (including the perspective of retailer or consumer).

The remedy to this problem probably lies in authors publishing (or making available on software) both the description and number of each type of healthcare resource used with the price or cost assigned to it. In that way, someone in the United Kingdom or Poland, or even another state in the United States, could substitute either their own unit price or number of resources they consumed. Rather than saying that an operation costs $\$ 10000$, if I knew it comprised four days in hospital at a cost of $\$ 2500$ a day, I could open up a computer spreadsheet and rerun the analysis using my own assumptions on the basis of the standard of care in my institution or setting and my cost per unit consumed in that setting.

Unfortunately, such information is often lacking. In my unpublished research on 125 studies (1996-2001) of cost effective devices in surgery, only five articles listed the unit costs, two listed the number of units consumed, and none listed both. The best information that can typically be found in even a great analysis is the cost per unit consumed (even that is often concealed for the sake of preserving proprietary information).

Authors and sponsors of pharmacoeconomic research need to realise that decision makers require an analysis that is sufficiently transparent; it can be customised for their own setting and include access to the underlying costs and resource consumption. Until then, I will continue to have doubts as to the extent to which such published material is being used by decision makers in any country.

Lorne E Basskin chair

Pharmacy Practice, Nova Southeastern University, 3200 South University Drive, Fort Lauderdale, FL 33328, USA lbasskin@nova.edu

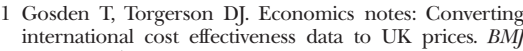
2002:325:275-6. (3 August.)

\section{Nitric oxide is not licensed for preterm neonates}

Editor-We agree with Pierce et al that attention should be drawn to the potential high cost of nitric oxide after the granting of its licence. ${ }^{1}$ The use of nitric oxide is not licensed for treating preterm neonates. The currently published evidence does not support the use of inhaled nitric oxide in preterm infants with hypoxic respiratory failure, and further randomised trials should be performed.

The increase in the cost of nitric oxide will be an important component in cost effectiveness studies as part of clinical trials of inhaled nitric oxide. Studies must be based on effectiveness data from long term follow up and the economic evaluation must take a broader account of costs, such as those to parents. It is also important to look at the cost (and not just the price from one supplier) of inhaled nitric oxide. Such a study is already at an advanced stage.

INNOVO (neonatal ventilation with inhaled nitric oxide versus ventilatory support without inhaled nitric oxide for severe respiratory failure) is an international randomised controlled trial funded by the Medical Research Council to investigate the clinical effectiveness and cost effectiveness of inhaled nitric oxide compared with conventional ventilatory care for preterm and for "mature" neonates with severe respiratory failure. The primary clinical outcome at 1 year of age (corrected for prematurity) is death or severe disability. The economic evaluation includes consideration of costs not only to the health services but also to parents. Recruitment is now closed, and follow up to age 4 is in progress. The results at 1 year of age should be available in 2003 .

Charles E M Normand head

Department of Epidemiology and Population Health, London School of Hygiene and Tropical Medicine, London WC1E 7HT

charles.normand@lshtm.ac.uk

David Field professor

Neonatal Unit, Leicester Royal Infirmary, Leicester LE1 5WW

Diana Elbourne professor of healthcare evaluation Ann Truesdale INNOVO trial coordinator

London School of Hygiene and Tropical Medicine

1 Pierce CM, Peters MJ, Coghen G, Goldman AP, Petros A Costs of nitric oxide is exorbitant. BMJ 2002;325:336. (10 August.)

2 Barrington KJ, Finer NN. Inhaled nitric oxide for respiratory failure in preterm infants. Cochrane Database Syst Rev 2001;4:CD000509.

\section{Physician assistants are useful in rheumatology}

EDITOR-My associate and I have had a busy practice limited to rheumatology, in addition to teaching students and residents at the local area medical school and publishing an occasional paper. Several years ago, we reached saturation point, when we were unable to accept referrals and consultations.

We employed a physician assistant, whom we trained to see return visits on long term patients. We did all initial visits and follow ups until the diagnosis was definitely established, treatment was started, and the patient's condition was stable. At that point the physician assistant would see the patient. The doctor would see the patient every third visit and would be available immediately if any question arose. We have since employed a second physician assistant, and a third will be starting in a few weeks, who will devote her time to patients with fibromyalgia. As a result, we are able to see patients referred to doctors in a timely manner and are the only rheumatologists to do so in a population area of over 1000000 people. 
Our physician assistants do a splendid job and improve in their ability month by month, but I would not recommend that they become independent practitioners. They are very effective in a subspecialty such as rheumatology, which is more cognitive than technical. They have allowed us to provide care that would otherwise be unavailable.

Alton J Morris rheumatologist

Arthritis Associates, 2202 John B Dennis Highway, Kingsport, TN 37660, USA

bubbas@chartertn.net

\section{Medical research charities should fund more trials}

EDITOR-Arguably clinical trials are the most important basis for evidence based medicine. So why are more such investigations not funded in the United Kingdom?

Both in 1999 and 2002 we sent a custom made questionnaire to all medicine charities listed in the Association of Medical Research Charities Handbook 2001, inquiring about the level of funding for clinical trials. ${ }^{1}$ Sixty two forms that could be evaluated were returned in 1999 and 60 in 2002, response rates of $62 \%$ (1999) and 55\% (2002), respectively. ${ }^{2}$

The question, "Do you fund clinical trials," was answered with a straight "No" in 35 (1999) and 29 (2002) instances. In 1999, the responding charities spent a total of $£ 3114396$ (\$4900 000; €4800 000) for support of clinical trials. In 2002, the corresponding figure was $£ 7924689$. The percentages of the total research budget spent on clinical trials were $2.3 \%$ (1999) and $5.0 \%$ (2002).

These results imply that, relative to their importance for evidence based medicine, the commitment to clinical trials by medical research charities in the United Kingdom remains small.

Edzard Ernst director of complementary medicine edzard.ernst@pms.ac.uk

Barbara Wider research assistant

b.wider@exeter.ac.uk

Complementary Medicine, Peninsula Medical School, Universities of Exeter and Plymouth, Exeter EX2 4NT

1 Association of Medical Research Charities. The Association of Medical Research Charities handbook 2001. London: AMRC, 2000.

2 Ernst E, Wider B. UK medical charities and clinical trials. Br J Gen Pract 1999;49:755.

\section{Thalidomide is not a human mutagen}

EDITOR-In 1994 McBride reported two cases of a malformed child born to fathers with thalidomide embryopathy. ${ }^{1}$ In case 1 the child had two unaffected brothers, and in case 2 the child had an unaffected older sibling. McBride suggested that thalidomide might be (the first) human germ cell mutagen. This contention was countered by several respondents, but several tabloid newspapers espoused the cause of the alleged second generation cases of thalidomide embryopathy. ${ }^{23}$ Subsequent to these exchanges a comprehensive experimental mutagenicity database was published, indicating that thalidomide was devoid of mutagenic activity. ${ }^{4}$

A major clinical evaluation of the hypothesis presented by McBride has just been published, and does not support it. ${ }^{5}$ Stromland et al conducted a retrospective study of the 88 Swedes recorded with thalidomide embryopathy between 1959 and 1963. Forty six of them were the parents of a total of 86 children, and 34 of the parents agreed to participate in the study. This allowed reference to 64 children: 29 girls and 35 boys. Five of the children had both parents with thalidomide embryopathy, 23 had mothers with thalidomide embryopathy, and 36 had fathers with thalidomide embryopathy. Caesarean sections were common, partly due to pelvic and uterine malformations induced by thalidomide. But malformations and functional anomalies typical of thalidomide embryopathy were not found among these 64 children.

Stromland et al noted that use of such a small population does not enable a mutagenic effect for thalidomide to be refuted; it only tells that there is no support for such an effect in that specific population. The data of Stromland et al therefore strengthen the current majority perception that thalidomide is not a human mutagen.

J Ashby senior research fellow

John.Ashby@Syngenta.com

$\mathbf{H}$ Tinwell researcher

Syngenta Central Toxicology Laboratory, Alderley Park, Macclesfield, Cheshire SK10 4TJ

Competing interests: None declared.

1 McBride WG. Thalidomide may be a mutagen. BMJ 1994; 308:1635-6.

2 Smithells RW. Thalidomide may be a mutagen. BMJ 1994; 309:477.

Ashby J and Tinwell H. Is thalidomide mutagenic? Nature 1995;375:453.

4 Ashby J, Tinwell H, Callander RD, Kimber I, Clay P, Galloway SM, et al. Thalidomide: lack of mutagenic activity across phyla and genetic endpoints. Mutat $R$ 1997:396:45-64.

5 Stromland K, Philipson E, Gronlund MA. Offspring of male and female parents with thalidomide embryopathy: male and female parents with thalidomide embryopathy: 66:115-21.

\section{Language evolution}

Patients were sectioned before ever they were consented

EDITOR-We write in response to the article by Aronson ${ }^{1}$ to point out that the apparently contemporary form of passive transformation "she was consented" is pre-dated by the widely prevalent description of the detention of a patient under any section of the Mental Health Act 1983: "s/he was sectioned."

Naresh D Gandhi consultant psychiatrist naresh.gandhi@cnwl.nhs.uk

Zeyn W Green-Thompson locum senior house officer Local Secure Services, Park Royal Centre for Mental Health, London NW10 7NS

1 Aronson J. When I use a word: Patient centred verbs. $B M J$ 2002;325:387. (17 August.)

\section{New tense has been invented}

EDIToR-I enjoy Aronson's seminars on the use of English. ${ }^{1}$ I wonder whether he has noticed the introduction into the language in recent years of a completely new tense?

Football commentators are responsible for this grammatical innovation. When describing what happened during the course of a match-and referring therefore to events in the past-they use the construction: "He's held the ball up too long, and Owen's got himself offside."

What should we call this tense?

The past revisited, perhaps?

Bob Bury consultant radiologist

Leeds General Infirmary, Leeds LS8 2JX

bob.bury@doctors.org.uk

1 Aronson J. When I use a word: Patient centred verbs. BMJ 2002;325:387. (17 August.)

\section{Roots of medical anatomical terms lie in both Sanskrit and Latin or Greek}

EDITOR-Medical terminology is a fascinating subject. ${ }^{1} \mathrm{I}$ am not an expert on any language, and my knowledge of Latin is mostly limited to medical and other scientific nomenclatures. In my high school days I was taught elementary Sanskrit, the ancient language of India, which predates Latin but belongs to the same group of Indo-European languages.

Roots of some medical anatomical terms in Latin or Greek and Sanskrit

\begin{tabular}{lll} 
Term & Latin or Greek & Sanskrit \\
\hline Tooth & Dens, dentalis & Danta \\
\hline Eye & Oculus, ocularis & Occu \\
\hline Mouth & Ostium & Ostto \\
\hline Bone & Os, ossis; osteon & Oshti \\
\hline Nose & Nasus & Nasika \\
\hline Umbilicus & Nafela* & Naavi \\
\hline Knee & Genu & Jaanu \\
\hline Foot & Podos & Podo \\
\hline Intestine & Enteron & Auntro \\
\hline
\end{tabular}

${ }^{*}$ Old English diminuitive of nafu, meaning the hub or central part of a wheel.

With my scanty linguistic knowledge, I can often relate a medical anatomical term to Sanskrit and Latin or Greek. I cite a few examples (table).

Kamal Samanta retired general practitioner Royds Park, Denby Dale, West Yorkshire HD8 8RN renkam@dircon.co.uk

1 Walker E. When I use a word: Pelvis. BMJ 2002;325:264. (3 August.)

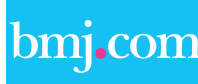

\section{Rapid responses}

Correspondence submitted electronically

is available on our website 